\title{
à la recherche de l'oubli
}

\section{perdu}

John Magerus

c'était à Honfleur--

joli petit port...

il pleuvait ce jour-1à--

jolie petite pluie

(en effet, ce n'était pas vraiment de la pluie--

mais je ne connais pas

le mot pour décrire

la condition atmosphérique

entre la pluie et le soleil)...

jolie petite pluie

j'étais assis dans un café tout près du port

il faisait un peu froid

et comme d'habitude

$j$ 'avais soif--

je t'assure

que ce n'était pas une petite soif 
je buvais du chocolat chaud

ce joli petit jour-1à

à Honfleur

en Normandie

et $j^{\prime}$ 'avais presque tout oublié . . .

quand tout à coup

cette gigantesque voiture est arrivée

s'est garée

et une femme

meublée d'un manteau blanc

garni de fourrure blanche

(de mauvaise qualité)

est descendue . .

c'était comme si un élèphant

était arrivé en youyou

ou comme si j'avais trouvé une grenouille

dans mon chocolat (chaud)...

cette femme vulgaire

m'a tout rappelé

TOUT

moi, je ne crois pas à l'inaction

agis! agis! criait mon coeur---

mais qu'est-ce qu'on peut faire

avec une femme très quelconque

qui porte un manteau blanc

garni de fourrure blanche

(mauvaise qualité)

quand il pleut une petite pluie froide

à Honfleur

en Normandie

1 'épouser

$?$

1a pousser dans $1^{\prime}$ eau 
as-tu jamais essayé

d'aimer un éléphant en youyou

de te réconcilier avec une grenouille

dans ton chocolat---n-----chaud

si oui

tu peux comprendre

la difficulté de la situation

ma philosophie

ne me permet pas

de considérer des questions

telles que:

pourquoi cette maudite femme

est-elle arrivée au moment

où j'ai presque tout oublié

I1 faut agir---

et $j^{\prime}$ ai agi

en me souvenant de ma colère

à cette intrusion

et prenant mon courage à deux mains

je suis sorti du café

je me suis précipité vers elle--

de grosses larmes dans les yeux

j'ai bousculé quelques passants

je suis tombé deux fois à genoux

et en même temps

je criais:

maman, maman

ma chère maman--

enfin je t'ai retrouvée . . . .

elle a manifesté une intelligence

que je n'aurais pas imaginée

à première vue

elle s'est sauvée 
sans un moment d'hésitation

elle a mis sa voiture en marche avec une rapidité incroyable--

I'a dé-garée

non sans heurter

les voitures à $I^{\prime}$ avant et à l'arrière-et a quitté Honfleur

la tranquillité a regagné la ville

je suis retourné au café

satisfait d'avoir empêché

une telle invasion

et pacifié---

j'ai retrouvé mon chocolat (tiède)

et j'ai recommencé à oublier

les éléphants

les grenouilles

la femme

presque tout---

Ah merde

et si elle était vraiment ma mère ! ?

The University of Kansas 


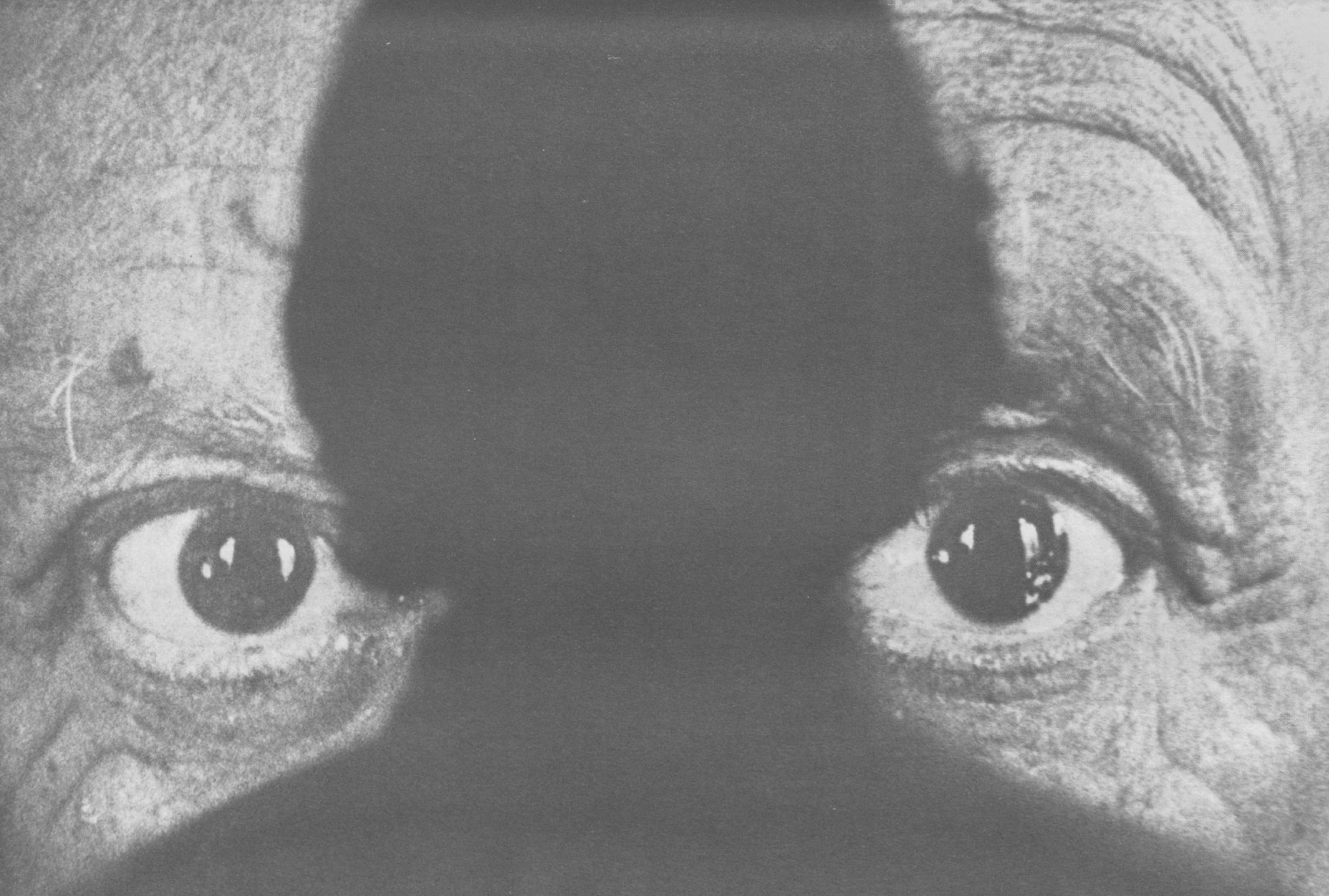

